\title{
Immobilization of Laccase in Alginate-Gelatin Mixed Gel and Decolorization of Synthetic Dyes
}

\author{
Mehdi Mogharabi, ${ }^{1,2}$ Nasser Nassiri-Koopaei, ${ }^{1}$ Maryam Bozorgi-Koushalshahi, ${ }^{1}$ \\ Nastaran Nafissi-Varcheh, ${ }^{3}$ Ghodsieh Bagherzadeh, ${ }^{2}$ and Mohammad Ali Faramarzi ${ }^{1,2}$ \\ ${ }^{1}$ Department of Pharmaceutical Biotechnology, Faculty of Pharmacy and Biotechnology Research Center, \\ Tehran University of Medical Sciences, P.O. Box 14155-6451, Tehran 14174, Iran \\ ${ }^{2}$ Department of Chemistry, Faculty of Sciences, University of Birjand, Birjand 9717853577, Iran \\ ${ }^{3}$ Department of Pharmaceutical Biotechnology, School of Pharmacy, Shahid Beheshti University of Medical Sciences, \\ Tehran 1457795343, Iran \\ Correspondence should be addressed to Mohammad Ali Faramarzi, faramarz@tums.ac.ir
}

Received 1 April 2012; Revised 10 June 2012; Accepted 15 June 2012

Academic Editor: Spyros Perlepes

Copyright (C) 2012 Mehdi Mogharabi et al. This is an open access article distributed under the Creative Commons Attribution License, which permits unrestricted use, distribution, and reproduction in any medium, provided the original work is properly cited.

\begin{abstract}
Alginate-gelatin mixed gel was applied to immobilized laccase for decolorization of some synthetic dyes including crystal violet. The immobilization procedure was accomplished by adding alginate to a gelatin solution containing the enzyme and the subsequent dropwise addition of the mixture into a stirred $\mathrm{CaCl}_{2}$ solution. The obtained data showed that both immobilized and free enzymes acted optimally at $50^{\circ} \mathrm{C}$ for removal of crystal violet, but the entrapped enzyme showed higher thermal stability compared to the free enzyme. The immobilized enzyme represented optimum decolorization at $\mathrm{pH} 8$. Reusability of the entrapped laccase was also studied and the results showed that $c$. $85 \%$ activity was retained after five successive cycles. The best removal condition was applied for decolorization of seven other synthetic dyes. Results showed that the maximum and minimum dye removal was related to amido black $10 \mathrm{~B}$ and eosin, respectively.
\end{abstract}

\section{Introduction}

While traditional methods in chemical processes have improved in the last decades, extensive attention has been paid to alternative techniques that utilize enzymes involving excellent characteristics, such as high activity, selectivity, and specificity. In addition, enzymes action at mild conditions of $\mathrm{pH}$, pressure, and temperature proposes them as candidates for suitable catalysts in industries where low cost, energy savings, and simplicity are important $[1,2]$. However, despite these advantages, some practical problems restrict their use, such as the high-cost isolation and purification process and instability in organic media and high temperatures. To overcome these limitations, several methods have been suggested and the most important of which are immobilization techniques [3, 4]. Enzyme entrapment uses natural and synthetic polymers, such as agarose, agar, and gelatin, through thermoreversal polymerization alginate, polyvinyl acetate, acrylic acid, and $\beta$-carrageenan by ionotropic gelation [5].

Gelatin consists of proteins and peptides produced by the denaturation of collagen, which breaks down into smaller fragments. Due to its unique physical properties, such as a melting point close to physiological temperature, gelatin is used in a variety of applications, especially in the food and pharmaceutical industries [6]. Gelatin immobilization methods have been developed for entrapment of microbial cells and enzymes, especially when the enzyme is placed in a whole cell. While the gelation process is reversible with temperature and displays no efficient immobilization, other than at $30-35^{\circ} \mathrm{C}$, some methods have been investigated to achieve an irreversible gelation process, such as using cross-link agents $[7,8]$. Single-step immobilization is one of the most frequently used methods of entrapment, which 
TABLE 1: Names, classification, maximum absorbance, and removal percentage of eight synthetic dyes using immobilized enzymes (in citrate buffer $0.1 \mathrm{M}$, pH 4.5).

\begin{tabular}{|c|c|c|c|c|}
\hline Name & Classification & $\lambda_{\max }$ & Dye removal (\%) & Removal rate $(\mathrm{nmol} / \mathrm{min})^{\mathrm{b}}$ \\
\hline Amido black 10B & Diazo & 618 & $86.9 \pm 1.3^{\mathrm{a}}$ & $22.5 \pm 2.3$ \\
\hline Bromothymol blue & Triphenylmethan & 430 & $53.8 \pm 1.2$ & $27.2 \pm 1.4$ \\
\hline Coomassie blue G-250 & Triphenylmethan & 575 & $71.4 \pm 0.8$ & $53.8 \pm 1.5$ \\
\hline Crystal violet & Triphenylmethan & 595 & $58.1 \pm 1.5$ & $95.3 \pm 2.8$ \\
\hline Eosin & Heterocyclic & 517 & $32.8 \pm 1.2$ & $20.1 \pm 1.2$ \\
\hline Malachite green & Triphenylmethan & 620 & $76.3 \pm 2.1$ & $120.7 \pm 2.5$ \\
\hline Methyl green & Triphenylmethan & 630 & $77.5 \pm 1.5$ & $73.4 \pm 1.4$ \\
\hline Methyl red & Azo & 522 & $52.1 \pm 1.8$ & $147.3 \pm 2.8$ \\
\hline
\end{tabular}

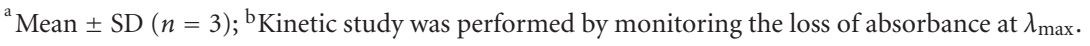

could be performed by simple gelation through lowering or raising temperatures of biopolymers such as agar, agarose, $\kappa$-carrageenan, and chitosan. Although it is easy to achieve, but this kind of preparation suffers from low mechanical strength and heat damages. Therefore, alternative methods are required to produce a more porous structure with higher mechanical stability and desirable elastic behavior. There are also some techniques for stabilization of alginate suggested by Birnbaum and colleagues which consists the treatment of alginate beads with polyethyleneimine- $\mathrm{HCl}$, activation of alginate with a mixture of 1-ethyl-3-(3-dimethyl-aminopropyl)-carbodiimide and N-hydroxysuccinimide, and addition of sodium metaperiodate to alginate [9].

Laccases (benzenediol:oxygen oxidoreductases, E.C. 1.10.3.2) are an interesting group of multicopper enzymes produced by higher plants and fungi that catalyze the oxidation of a wide range of organic compounds, such as phenols, in the presence of molecular oxygen $[10,11]$. The most important applications discussed for laccases include pharmaceutical and food industries, textile effluent transformation, and wastewater detoxification biosensors. The unique properties of laccases, such as high stability in solution, mild reaction conditions, and selectivity for phenolic structure, make them attractive for use in chemical synthesis [12]. The mechanism of phenolic ring oxidation by laccase has been previously described. Releasing molecular nitrogen, instead of the formation of low molecular weight aromatic amines that are easily absorbed through the skin and known as powerful carcinogens and mutagens, could be considered as an advantage for using laccase for detoxification of synthetic dyes especially aromatic azo dyes [13].

Wastewater released by various industries that use synthetic dyes because of their low cost, ease of synthesis, and color variety can pollute and harm the aquatic environment. Decolorization of synthetic dyes by using special biocatalysts has received great attention because of efficient decolorization and nontoxic product generation $[14,15]$. Crystal violet is a widely used synthetic pigment for dye processing. It is stable and nondegradable by conventional methods and has been identified as a main factor of industrial effluent contamination. Textile factories are under pressure to apply environmental-friendly technologies to remove it [16].
The aim of the present study was to apply alginategelatin mixed gel to immobilize laccase, which is further employed in the decolorization of some synthetic dyes, such as crystal violet, in aqueous solutions. Optimum $\mathrm{pH}$, temperature, and proper enzyme content for decolorization by the immobilized laccase were also studied. To our knowledge, the use of alginate-gelatin mixed gel has not been examined previously for the purpose of enzyme entrapment.

\section{Experimental}

2.1. Chemicals and Instruments. Crystal violet, coomassie blue G-250, bromothymol blue, amido black 10B, methyl red, eosin, and malachite green (Table 1) were purchased from Sigma-Aldrich (St. Louis, MO, USA). Gelatin and sodium alginate were obtained from Merck (Darmstadt, Germany). All other reagents and chemicals were of the highest purity available. Extracellular laccase was purified from the submerged fermentation of the soil isolate ascomycete Paraconiothyrium variabile $[10,17,18]$. Decolorization was monitored by UV-VIS spectroscopy. Absorbance was scanned by a double-beam UV-Vis 2501 PC spectrophotometer (Shimadzu, Japan). The mechanical force to break the beads was measured with a tensiometer (Zwick/Roell 030, Germany). Optical images of the gelatin-alginate beads were taken with a USB Digital Microscope Pro (Dino-Lite, Taiwan). Scanning electron microscope (SEM, Hitachi S2400, Japan) was applied for studying the size and surface of the beads.

2.2. Preparation of Mixed Gels, Immobilization of Laccase, and Decolorization of Crystal Violet. The gelatin-alginate mixed gel was prepared according to the method of Panouille and Larreta-Garde [19], with some modifications. Briefly, entrapment of laccase in gelatin-alginate mixed gel was performed by adding $0.1 \mathrm{~g}$ sodium alginate to $10 \mathrm{~mL}$ of a solution containing $10 \%(\mathrm{w} / \mathrm{v})$ gelatin and laccase in the range of $5-50 \mathrm{mg}$ ( $1 \mathrm{mg}$ enzyme is equal to $1.25 \mathrm{U}$ ) under continuous stirring at room temperature. The mixture was syringed into a stirring $\mathrm{CaCl}_{2}$ solution $(200 \mathrm{mM})$, and the resulting beads were left to be harden for $1 \mathrm{~h}$ under the same conditions, washed three times by deionized water, and 
TABLE 2: Maximum force required to rupture beads and the amount of bound protein.

\begin{tabular}{lcc}
\hline Alginate & Maximum force $(\mathrm{kgf})$ & Bound protein $(\mathrm{mg} / \mathrm{g}$ carrier $)$ \\
\hline $1 \%$ & $0.125 \pm 0.033^{\mathrm{a}}$ & $0.063 \pm 0.035^{\mathrm{b}, \mathrm{c}}$ \\
$2 \%$ & $0.152 \pm 0.041$ & $0.094 \pm 0.043$ \\
$3 \%$ & $0.161 \pm 0.037$ & $0.127 \pm 0.080$ \\
$4 \%$ & $0.177 \pm 0.047$ & $0.153 \pm 0.075$ \\
$5 \%$ & $0.204 \pm 0.063$ & $0.166 \pm 0.098$ \\
\hline
\end{tabular}

${ }^{\mathrm{a}}$ Mean $\pm \mathrm{SD}(n=20) ;{ }^{\mathrm{b}}$ Mean $\pm \mathrm{SD}(n=3) ;{ }^{\mathrm{c}}$ Beads was washed with $50 \mathrm{mM}$ citrate buffer ( $\mathrm{pH}$ 5.0).

then stored at $4{ }^{\circ} \mathrm{C}$ prior to being used in the decolorization study. The amount of bound protein was determined by Bradford's method [20], using the following equation: $Q=$ $(C i-C f) / m V$, where $Q$ was the bound enzyme (mg enzyme/g beads), $C i$ and $C f$ were the initial and final enzyme concentrations in the solution $(\mathrm{mg} / \mathrm{mL}), V$ was the volume of the solution $(\mathrm{mL})$, and $m$ was the mass of the beads $(\mathrm{g})$. The immobilized laccase $(10 \mathrm{~g})$ was transferred into a $20 \mathrm{~mL}$ buffer solution, at $\mathrm{pH} 3-9$, containing crystal violet (final concentration $0.083 \mathrm{mM}$ ), at a $30-70^{\circ} \mathrm{C}$ temperature range, for $20 \mathrm{~min}$. Maximum absorbance was monitored according to $\lambda_{\max }$ of the dye (Table 1). Relative decolorization was calculated by the following equation: relative decolorization $(\%)=\left(A_{\text {initial }}-A_{\text {final }}\right) / A_{\text {initial }} \times 100$, where $A_{\text {initial }}$ was the initial absorbance and $A_{\text {observed }}$ was the final absorbance at the given wavelength.

2.3. Optimum Temperature, PH, and Enzyme Concentration of the Immobilized Laccase. The effect of $\mathrm{pH}$ on the enzymatic decolorization was monitored with a dye concentration of $0.25 \mathrm{mg} / \mathrm{mL}$ at a 3-9 $\mathrm{pH}$ range adjusted by citrate or ammonia buffers. To determine the effect of temperature on the enzymatic decolorization, the reaction mixture was incubated at a thermal range of $30-70^{\circ} \mathrm{C}$, in steps of $10^{\circ} \mathrm{C}$. In order to assess the effect of enzyme quantity on decolorization, the reaction was started with different enzyme amounts, from 0.25 to $0.5 \mathrm{mg} / \mathrm{mL}$, in $0.05 \mathrm{mg} / \mathrm{mL}$ increments. The experiments were performed in triplicate; the results shown are means \pm standard deviation.

2.4. Mechanical Strength, Optical Image, and SEM. The force required to rupture the beads was recorded by compressing the beads using a tensiometer; the results are the average force from 20 independent tests. The optical microscopy was used to evaluate the shape, surface, and size of the beads, and scanning electron microscopy (SEM) was also applied to study the structure of the fabricated beads.

2.5. Reusability. Reusability of the gelatin-alginate immobilized enzyme was investigated in acetate buffer solution $0.1 \mathrm{M}$ at $\mathrm{pH} 8$ and $45^{\circ} \mathrm{C}$. The used beads were filtered at the end of each cycle and washed three times with the same buffer to treat in the next fresh colored solution. The reusability study was performed in triplicate.
2.6. Decolorization of Synthetic Dyes. Decolorization of the other dyes from the aqueous solution-coomassie blue G-250 $(0.086 \mathrm{mM})$, bromothymol blue $(0.095 \mathrm{mM})$, amido black 10B $(0.045 \mathrm{mM})$, methyl red $(0.125 \mathrm{mM})$, eosin $(0.038 \mathrm{mM})$, and malachite green $(0.112 \mathrm{mM})$ - was investigated by adding $10 \mathrm{~g}$ immobilized laccase to $20 \mathrm{~mL}$ citrate buffer solution $(0.1 \mathrm{M}, \mathrm{pH} 4.5)$ containing dye, at $45^{\circ} \mathrm{C}$ for $20 \mathrm{~min}$. Relative decolorization was calculated as described above for crystal violet. Some properties of the applied synthetic dyes and the percentages of dye removal are shown in Table 1. Standard deviation and mean of the results from three independent experiments were calculated using SigmaPlot for Windows (version 10.0).

\section{Results and Discussion}

3.1. Effect of Experimental Parameters on Crystal Violet Decolorization. Spherical and regular-shaped gelatinalginate beads were obtained by using ionotropic gelation; the diameters of the beads were $2.0-2.5 \mathrm{~mm}$ (Figure 1(a)). The results, as shown in Table 2, indicated the rupture force increase with the rise in alginate concentration. The prepared beads containing $5 \%$ alginate exhibited the highest mechanical stability. Alginate could provide a very strong network that required $0.204 \mathrm{kgf}$ force to rupture. Earlier studies had also reported a direct correlation between rupture force and alginate concentration [21].

Among the investigated parameters, $\mathrm{pH}$ plays the key role in dye decolorization. The effect of $\mathrm{pH}$ on dye decolorization was examined at $\mathrm{pH}$ ranging from 3 to 9 , using acetate $(\mathrm{pH}$ 3-6) and ammonia ( $\mathrm{pH} \mathrm{7-9)} \mathrm{buffers.} \mathrm{The} \mathrm{crude} \mathrm{enzyme}$ significantly displayed higher decolorization activity in basic $\mathrm{pH}$ (Figure 2) with a sharp increase at $\mathrm{pH}$ values above 6 and maximum activity at $\mathrm{pH}$ 9. The optimal $\mathrm{pH}$ for the immobilized enzyme activity was 8 . It shows that $\mathrm{pH}$ of the environment has significant effects on decolorization which suggests that the mass transfer in the gel matrix may depend on the transport of bulk $\mathrm{H}^{+}$ion into the gel matrix [22].

The effect of temperature on dye decolorization was investigated by changing the reaction mixture temperatures in a $30-70^{\circ} \mathrm{C}$ range. The results obviously showed that decolorization increased as the temperature raised up to $50^{\circ} \mathrm{C}$; at higher temperatures, decolorization efficiency remarkably decreased, which normally attributed to denaturation of enzyme. However, the comparison of decolorization results indicated high thermal stability of immobilized enzyme and confirmed the protective role of alginate-gelatin mixed gel for maintaining enzyme activity. At $50^{\circ} \mathrm{C}$, the crude and immobilized enzymes exhibited more activity, as shown in Figure 3. Similarly, Forootanfar and colleagues [10] reported that the optimum temperature for laccase activity was $50^{\circ} \mathrm{C}$. Other research studies have reported an optimum temperature range of $45-50^{\circ} \mathrm{C}$ for laccase activity immobilized by both covalent binding and adsorption [23, 24].

To determine the proper amount of enzymes required for maximum decolorization, the effect of enzyme quantity on dye decolorization was also studied. As shown in Figure 4, decolorization increased as enzyme quantity increased, from 


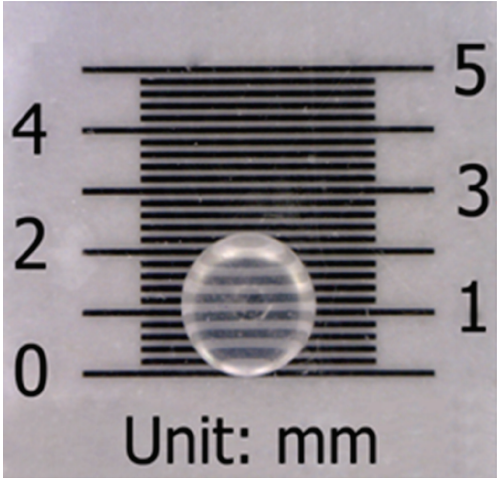

(a)

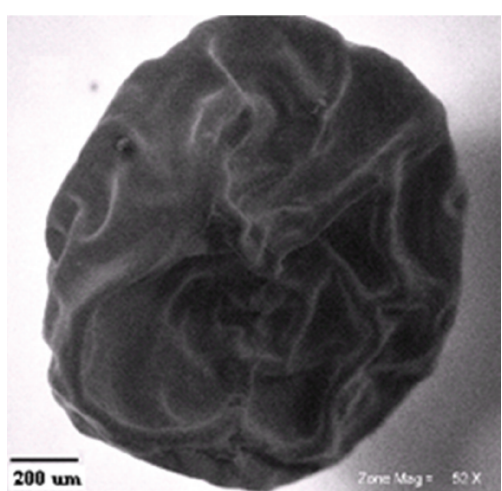

(b)

FIgURE 1: Optical image (a) and SEM of the prepared gelatin-alginate bead (b).

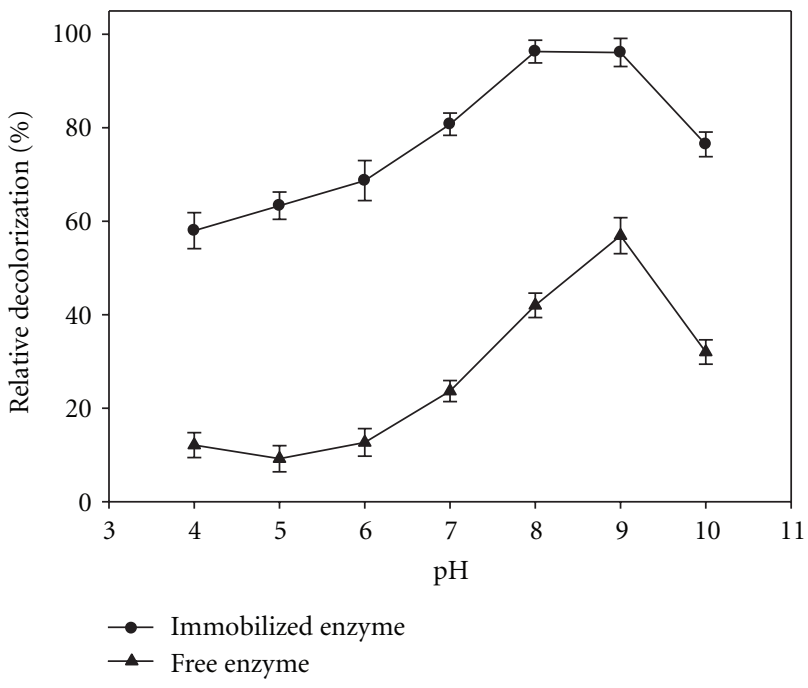

Figure 2: Effect of $\mathrm{pH}$ on relative decolorization activity of free laccase $(\boldsymbol{\Delta})$ and immobilized laccase $(\bullet)$. Data were mean values \pm SD.

0.5 to $5 \mathrm{mg} / \mathrm{mL}$. However, the results demonstrated that the minimum enzyme quantity to obtain maximum decolorization was $2.5 \mathrm{mg} / \mathrm{mL}$.

The optimum conditions were obtained as described above and applied for the decolorization of other synthetic dyes (Table 1). It is notable that the efficiency of laccase enzyme for removal and detoxification of these synthetic dyes has been previously reported and discussed $[13,25,26]$. The results showed that amido black $10 \mathrm{~B}$ and eosin exhibited maximum and minimum dye removal, respectively. It was observed that the immobilized laccase was able to decolorize more than $80 \%$ of amido black 10B, while Selvam and colleagues [27] reported $15 \%$ decolorization by laccase. However, all of the dyes were oxidized at the maximum rate in $\mathrm{pH}$ 8. Kinetic studies (Table 1) suggested that among the used dye substrates for the enzymatic removal, methyl red and malachite green are preferred, and, in contrast, eosin is a poor substrate [13].

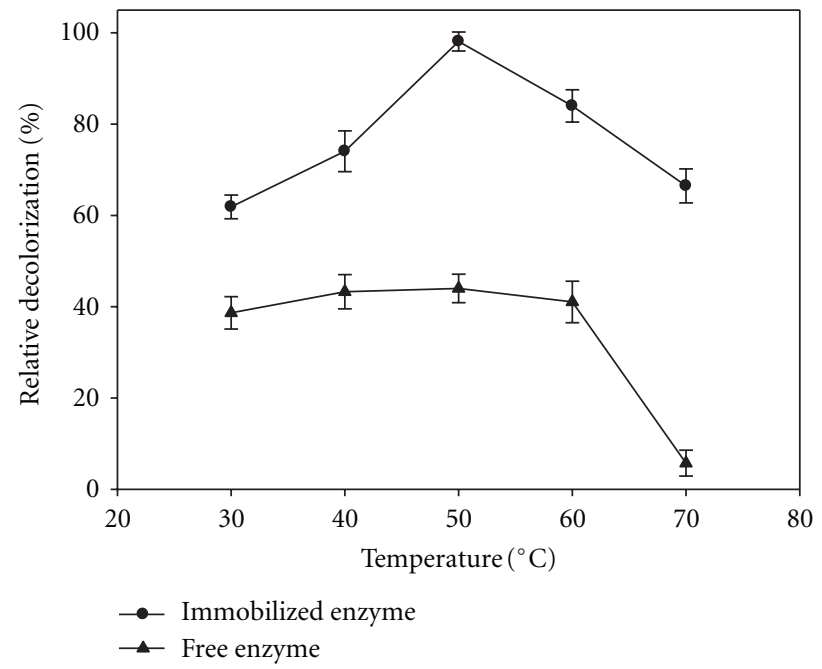

Figure 3: Influence of temperature on relative decolorization activity of free laccase $(\boldsymbol{\Delta})$ and immobilized laccase $(\bullet)$. Data were mean values $\pm \mathrm{SD}$.

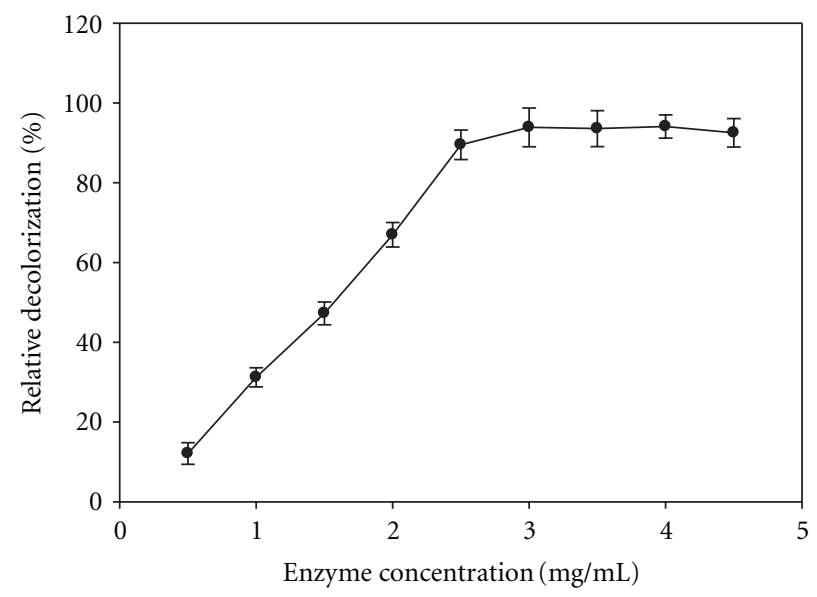

FIGURE 4: Effect of enzyme concentration on relative decolorization activity of the immobilized laccase. Data were mean values \pm SD. 


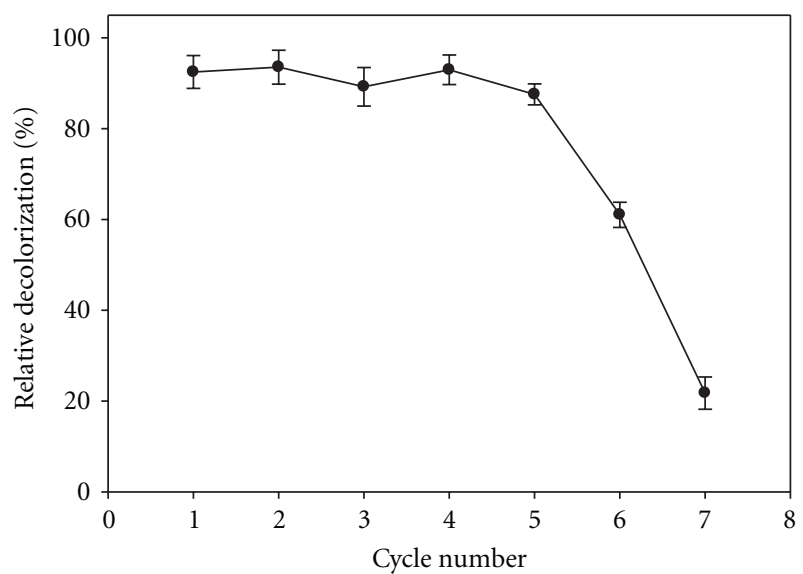

FIGURE 5: Reusability of immobilized laccase in the reaction condition. Data were mean values \pm SD.

3.2. Reusability of Immobilized Laccase. Reusability of immobilized enzymes exhibits the most important aspect for industrial applications, because immobilization of enzymes decreases the cost of production due to their repeated continuous uses. In this work, reusability of the immobilized enzyme was investigated up to seven cycles; the residual activities are presented in Figure 5. During enzymatic reactions, the alginate-gelatin mixture may cause a decrease in the pore sizes of the network, leading to difficulties in the diffusion of the substrate and product in the matrix of the gel. This restriction may cause a decrease in the efficient activity of laccase entrapped in gel after repeated use. In the literature, there are reports of successful reuses of various immobilized laccase systems, such as $60 \%$ activity after ten cycles for covalently immobilized laccase on activated polyvinyl alcohol [28-30] and 80\% after five cycles for laccase immobilized on amine-terminated magnetic nanocomposites by cross-linking method [31].

\section{Conclusions}

Immobilization of laccase has received increasing attention in dye removal of aqueous solutions such as wastewater. Gelatin-alginate beads were prepared as a matrix system for laccase entrapment; the immobilized enzymes exhibited more stability during operation compared to free enzymes, a result that can be considered an advantage in wastewater treatment. In addition, the reusability of gelatin-alginate beads provides economic benefits when used in largescale applications. Future investigations may focus on the decolorization of different types of dyes that are widely used in the chemical and textile industries.

\section{Acknowledgment}

This work was financially supported by Grant no. 90-04-3316360 from Tehran University of Medical Sciences, Tehran, Iran.

\section{References}

[1] Z. Konsoula and M. Liakopoulou-Kyriakides, "Thermostable $\alpha$-amylase production by Bacillus subtilis entrapped in calcium alginate gel capsules," Enzyme and Microbial Technology, vol. 39, no. 4, pp. 690-696, 2006.

[2] C. Silva, C. J. Silva, A. Zille, G. M. Guebitz, and A. CavacoPaulo, "Laccase immobilization on enzymatically functionalized polyamide 6,6 fibres," Enzyme and Microbial Technology, vol. 41, no. 6-7, pp. 867-875, 2007.

[3] G. D. Altun and S. A. Cetinus, "Immobilization of pepsin on chitosan beads," Food Chemistry, vol. 100, no. 3, pp. 964-971, 2007.

[4] F. Van De Velde, N. D. Lourenço, H. M. Pinheiro, and M. Bakker, "Carrageenan: a food-grade and biocompatible support for immobilization techniques," Advanced Synthesis and Catalysis, vol. 344, no. 8, pp. 815-835, 2002.

[5] S. M. Kotwal and V. Shankar, "Immobilized invertase," Biotechnology Advances, vol. 27, no. 4, pp. 311-322, 2009.

[6] C. Joly-Duhamel, D. Hellio, and M. Djabourov, "All gelatin networks: 1. Biodiversity and physical chemistry," Langmuir, vol. 18, no. 19, pp. 7208-7217, 2002.

[7] L. J. Yang and Y. C. Ou, "The micro patterning of glutaraldehyde (GA)-crosslinked gelatin and its application to cellculture," Lab on a Chip, vol. 5, no. 9, pp. 979-984, 2005.

[8] A. Tanriseven and S. Doğan, "A novel method for the immobilization of $\beta$-galactosidase," Process Biochemistry, vol. 38, no. 1, pp. 27-30, 2002.

[9] S. Birnbaum, R. Pendleton, P. O. Larsson, and K. Mosbach, "Covalent stabilization of alginate gel for the entrapment of living whole cells," Biotechnology Letters, vol. 3, no. 8, pp. 393400, 1981.

[10] H. Forootanfar, M. A. Faramarzi, A. R. Shahverdi, and M. T. Yazdi, "Purification and biochemical characterization of extracellular laccase from the ascomycete Paraconiothyrium variabile," Bioresource Technology, vol. 102, no. 2, pp. 1808$1814,2011$.

[11] H. Forootanfar, M. M. Movahednia, S. Yaghmaei et al., "Removal of chlorophenolic derivatives by soil isolated ascomycete of Paraconiothyrium variabile and studying the role of its extracellular laccase," Journal of Hazardous Materials, vol. 209-210, pp. 199-203, 2012.

[12] S. R. Couto and J. L. T. Herrera, "Industrial and biotechnological applications of laccases: a review," Biotechnology Advances, vol. 24, no. 5, pp. 500-513, 2006.

[13] M. Chivukula and V. Renganathan, "Phenolic azo dye oxidation by laccase from Pyricularia oryzae," Applied and Environmental Microbiology, vol. 61, no. 12, pp. 4374-4377, 1995.

[14] A. Kunamneni, I. Ghazi, S. Camarero, A. Ballesteros, F. J. Plou, and M. Alcalde, "Decolorization of synthetic dyes by laccase immobilized on epoxy-activated carriers," Process Biochemistry, vol. 43, no. 2, pp. 169-178, 2008.

[15] G. K. Parshetti, A. A. Telke, D. C. Kalyani, and S. P. Govindwar, "Decolorization and detoxification of sulfonated azo dye methyl orange by Kocuria rosea MTCC 1532," Journal of Hazardous Materials, vol. 176, no. 1-3, pp. 503-509, 2010.

[16] H. J. Fan, S. T. Huang, W. H. Chung, J. L. Jan, W. Y. Lin, and C. C. Chen, "Degradation pathways of crystal violet by Fenton and Fenton-like systems: condition optimization and intermediate separation and identification," Journal of Hazardous Materials, vol. 171, no. 1-3, pp. 1032-1044, 2009.

[17] M. A. Faramarzi and H. Forootanfar, "Biosynthesis and characterization of gold nanoparticles produced by laccase 
from Paraconiothyrium variabile," Colloids and Surfaces B, vol. 87, no. 1, pp. 23-27, 2011.

[18] M. Aghaie-Khouzani, H. Forootanfar, M. Moshfegh, M. R. Khoshayand, and M. A. Faramarzi, "Decolorization of some synthetic dyes using optimized culture broth of laccase producing ascomycete Paraconiothyrium variabile," Biochemical Engineering Journal, vol. 60, no. 1, pp. 9-15, 2012.

[19] M. Panouillé and V. Larreta-Garde, "Gelation behaviour of gelatin and alginate mixtures," Food Hydrocolloids, vol. 23, no. 4, pp. 1074-1080, 2009.

[20] M. M. Bradford, "A rapid and sensitive method for the quantitation of microgram quantities of protein utilizing the principle of protein dye binding," Analytical Biochemistry, vol. 72, no. 1-2, pp. 248-254, 1976.

[21] A. K. Anal and W. F. Stevens, "Chitosan-alginate multilayer beads for controlled release of ampicillin," International Journal of Pharmaceutics, vol. 290, no. 1-2, pp. 45-54, 2005.

[22] J. P. Chen and Y. S. Lin, "Decolorization of azo dye by immobilized Pseudomonas luteola entrapped in alginate-silicate sol-gel beads," Process Biochemistry, vol. 42, no. 6, pp. 934-942, 2007.

[23] X. Hu, X. Zhao, and H. M. Hwang, "Comparative study of immobilized Trametes versicolor laccase on nanoparticles and kaolinite," Chemosphere, vol. 66, no. 9, pp. 1618-1626, 2007.

[24] G. Hublik and F. Schinner, "Characterization and immobilization of the laccase from Pleurotus ostreatus and its use for the continuous elimination of phenolic pollutants," Enzyme and Microbial Technology, vol. 27, no. 3-5, pp. 330-336, 2000.

[25] X. Q. Yang, X. X. Zhao, C. Y. Liu, Y. Zheng, and S. J. Qian, "Decolorization of azo, triphenylmethane and anthraquinone dyes by a newly isolated Trametes sp. SQ01 and its laccase," Process Biochemistry, vol. 44, no. 10, pp. 1185-1189, 2009.

[26] G. K. Parshetti, S. G. Parshetti, A. A. Telke, D. C. Kalyani, R. A. Doong, and S. P. Govindwar, "Biodegradation of crystal violet by Agrobacterium radiobacter," Journal of Environmental Sciences, vol. 23, no. 8, pp. 1384-1393, 2011.

[27] K. Selvam, K. Swaminathan, and K. S. Chae, "Decolourization of azo dyes and a dye industry effluent by a white rot fungus Thelephora sp," Bioresource Technology, vol. 88, no. 2, pp. 115119, 2003.

[28] D. Yinghui, W. Qiuling, and F. Shiyu, "Laccase stabilization by covalent binding immobilization on activated polyvinyl alcohol carrier," Letters in Applied Microbiology, vol. 35, no. 6, pp. 451-456, 2002.

[29] N. Vishal Gupta, D. V. Gowda, V. Balamuralidhara, and S. Mohammed Khan, "Formulation and evaluation of olanzapine matrix pellets for controlled release," DARU, Journal of Pharmaceutical Sciences, vol. 19, no. 4, pp. 249-256, 2011.

[30] F. G. Mutti, R. Pievo, M. Sgobba, M. Gullotti, and L. Santagostini, "Biomimetic modeling of copper complexes: a study of enantioselective catalytic oxidation on $D$-(+)-catechin and $L-(-)$-epicatechin with copper complexes," Bioinorganic Chemistry and Applications, vol. 2008, Article ID 762029, 9 pages, 2008.

[31] H. Y. Xiao, J. Huang, C. Liu, and D. S. Jiang, "Immobilization of laccase on amine-terminated magnetic nano-composite by glutaraldehyde crosslinking method," Transactions of Nonferrous Metals Society of China, vol. 16, supplement 1, pp. s414s418, 2006. 


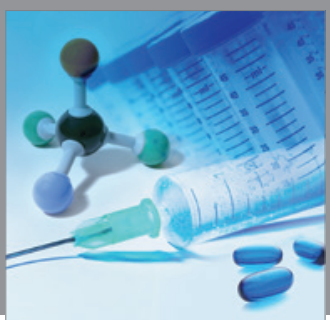

International Journal of

Medicinal Chemistry

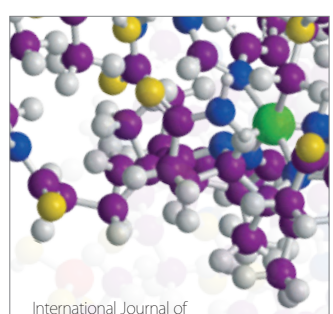

Carbohydrate Chemistry

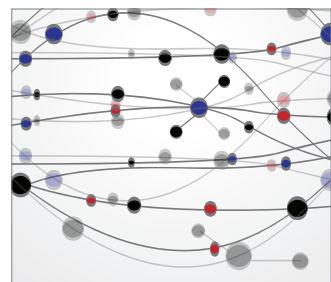

The Scientific World Journal
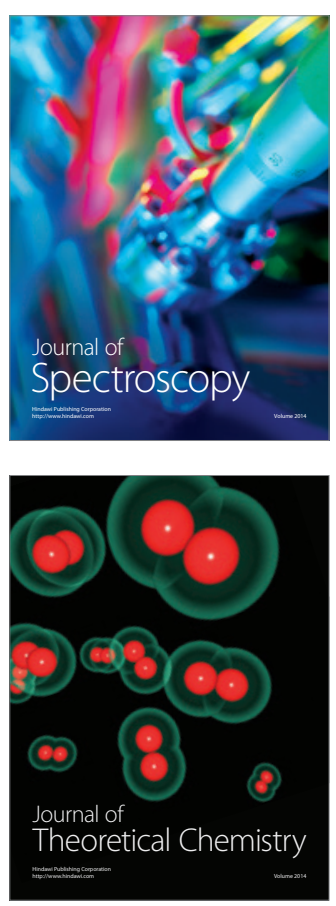
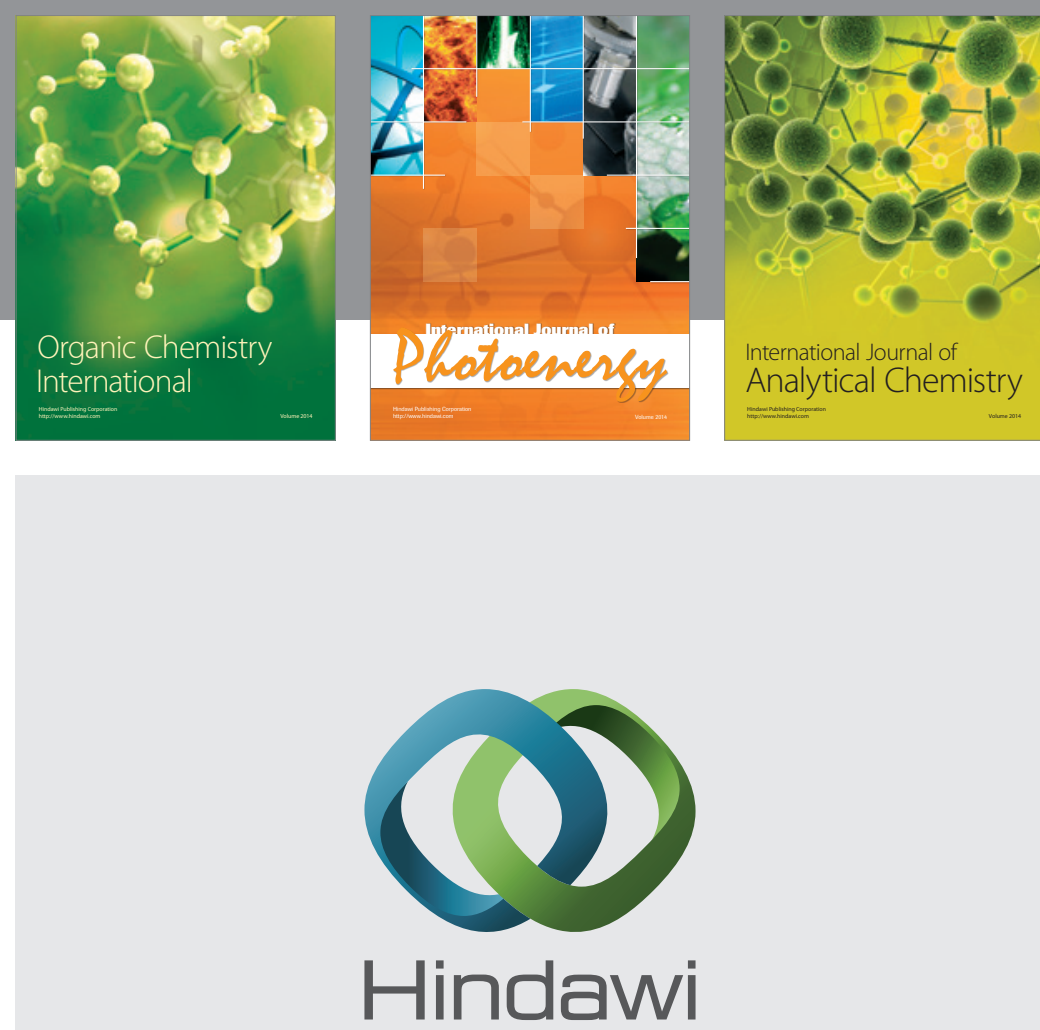

Submit your manuscripts at

http://www.hindawi.com
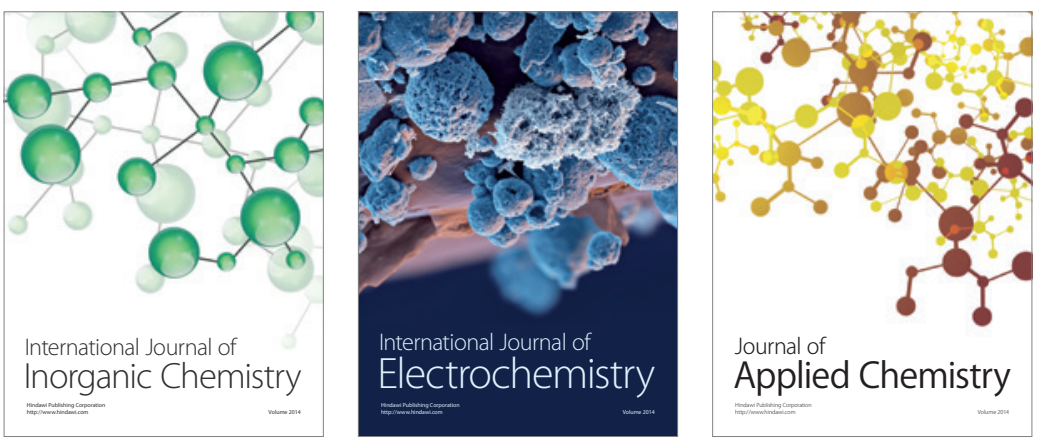

Journal of

Applied Chemistry
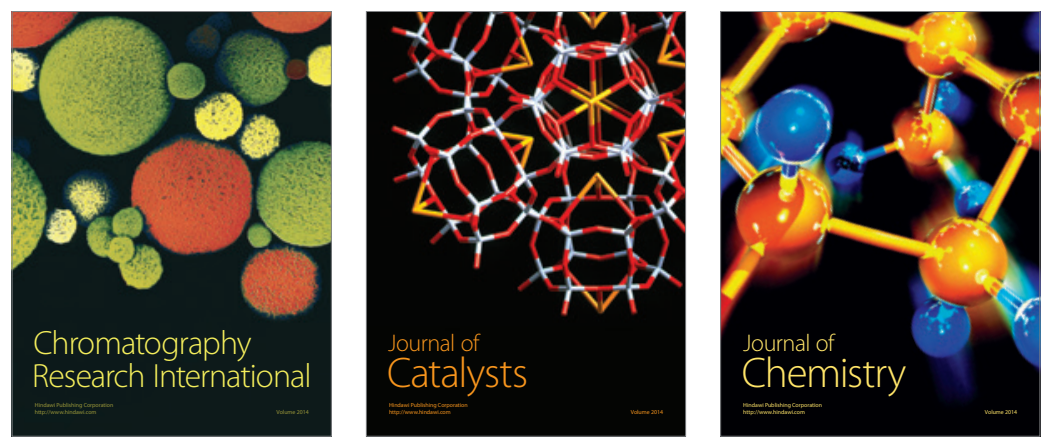
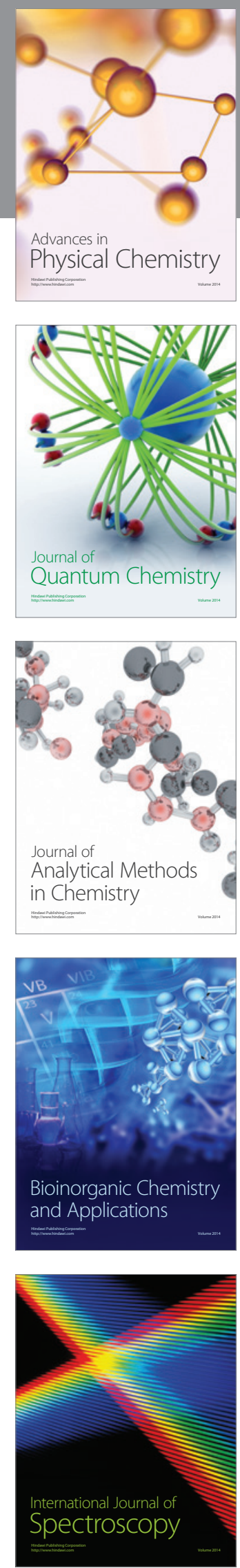